Case Report

\title{
Hormonal Treatment for Severe Hydronephrosis Caused by Bladder Endometriosis
}

\author{
Erkan Efe, ${ }^{1}$ Murat Bakacak, ${ }^{2}$ Salih Serin, ${ }^{2}$ Eyüp Kolus, ${ }^{1}$ Önder Ercan,, and Sefa Resim ${ }^{1}$ \\ ${ }^{1}$ Department of Urology, Kahramanmaraş Sütçü Imam School of Medicine, Turkey \\ ${ }^{2}$ Department of Obstetrics and Gynecology, Kahramanmaraş Sütçü Imam School of Medicine, Kahramanmaras, Turkey
}

Correspondence should be addressed to Murat Bakacak; muratbakacak46@gmail.com

Received 14 September 2014; Accepted 6 November 2014; Published 18 November 2014

Academic Editor: Apul Goel

Copyright (C) 2014 Erkan Efe et al. This is an open access article distributed under the Creative Commons Attribution License, which permits unrestricted use, distribution, and reproduction in any medium, provided the original work is properly cited.

\begin{abstract}
The incidence of endometriosis cases involving the urinary system has recently increased, and the bladder is a specific zone where endometriosis is most commonly seen in the urinary system. In the case presented here, a patient presented to the emergency department with the complaint of side pain and was examined and diagnosed with severe hydronephrosis and bladder endometriosis was determined in the etiology. After the patient was pathologically diagnosed, Levonorgestrel-Releasing Intrauterine System (LNG-IUS) was administered to the uterine cavity. At the 12-month follow-up, endometriosis was not observed in the cystoscopy and symptoms had completely regressed. Hydronephrosis may be observed after exposure of the ureter, and silent renal function loss may develop in patients suffering from endometriosis with bladder involvement. For patients with moderate or severe hydronephrosis associated with bladder endometriosis, LNG-IUS application may be separately and successfully used after conservative surgery.
\end{abstract}

\section{Introduction}

Endometriosis is defined as the appearance of the endometrial gland and stroma outside the uterus. Ectopic endometrial tissues are generally detected in the pelvis, although they may be observed anywhere in the body. Benign endometriosis is a chronic and estrogen-dependent disease, which may classically trigger certain symptoms such as pelvic pain, severe dysmenorrhea, dyspareunia, and infertility $[1,2]$. On the other hand, deep infiltrating endometriosis (DIE) generally influences uterosacral ligaments, the rectovaginal region, posterior vaginal wall, intestines, and urinary system $[3,4]$.

The incidence of endometriosis cases involving the urinary system has recently increased, with reported rates of approximately $0.3-12 \%$ of all patients diagnosed with endometriosis [4-11]. The bladder is a specific zone of the urinary system where endometriosis is most commonly seen and bladder involvement is seen in approximately $85 \%$ of urinary system involvement endometriosis cases. To date, 350 cases have been defined in the literature [11]. In bladder endometriosis, the symptoms of the patient may vary according to the localization and dimensions of the lesion [1113]. Basically, the most commonly encountered symptoms are acute urethral syndrome, tenesmus, burning sensation in the urinary tract, dysuria, suprapubic sensitivity, and pain accompanied by thamuria [11-17]. Menouria during the menstrual period is a symptom which is not encountered as commonly as acute urethral syndrome and which is seen in only $20-25 \%$ of the patients with mucosal involvement [17].

In this paper, it was aimed to review literature in conjunction with analysis of a case where a patient presented to the emergency department with the complaint of side pain and was diagnosed with severe hydronephrosis and bladder endometriosis was determined in the etiology. Successful treatment was applied using the Levonorgestrel-Releasing Intrauterine System (LNG-IUS).

\section{Case}

A 29-year-old female presented to the emergency department with the complaint of left side pain. Sensitivity in the left costovertebral region was detected during physical examination. No kind of operation or chronic disease was 


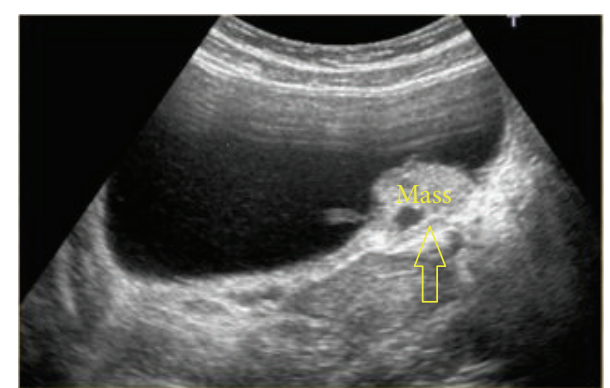

FIGURE 1: Urinary system ultrasonography showing a massive lesion of $3 \times 4 \mathrm{~cm}$ extending into the bladder on the left side wall of the bladder.

recorded in the medical history and family history of the patient. Creatinine value was found to be $1.37 \mathrm{ng} / \mathrm{dL}$ in the blood biochemistry examination. In the urinary system ultrasonography (USG), it was observed that the right kidney was atrophic, that the left ureter was dilated as far as the ureterovesical junction, that there was grade III hydronephrosis in the left kidney, and that there was a massive lesion of $3 \times 4 \mathrm{~cm}$ extending into the bladder on the left side wall of the bladder (Figure 1). In each abdominal contrast Computed Tomography (CT) scan of the patient, it was seen that the left ureter and renal pelvis were severely dilated and that there was a massive lesion of $3 \times 4 \mathrm{~cm}$ extending into the bladder on the left ureter orifice on the left side wall of the bladder (Figure 2). In the medical history of the patient, it was recorded that the patient had complaints of hematuria and severe pelvic pain which had been ongoing for 4-5 menstrual cycles. On transvaginal USG, a mass of $4 \times 4 \mathrm{~cm}$ of cystic appearance was detected in simple form in the left ovary. In cystoscopy, the left orifice could not be seen although the right orifice was monitored. A red-colored solid lesion in the papillary structure was observed in the left area conforming to the symmetry of the right orifice. The lesion was partially resected by resectoscope. The resected material was sent to the pathology laboratory for histological examination. Percutaneous nephrostomy was attached to the left kidney under USG guidance. Contrast material was administered to the patient through the nephrostomy catheter, and anterograde pyelography was taken. It was observed that the contrast material was not transmitted to the bladder in the ureterovesical junction (Figure 3). At follow-up examinations, within 3 days, the hydronephrosis in the left kidney had receded and the serum creatinine value was determined to have returned to normal limits. The nephrostomy catheter was removed on the third day as renal functions had returned to normal and the hydronephrosis had receded. The final pathology result of the resected material was reported as "endometriosis" (Figure 4). The patient was referred to the gynaecology clinic. The tumor markers of the patient were determined as Ca 125: $92.2 \mu / \mathrm{mL}$ $(0-35 \mu / \mathrm{mL})$ and Ca 19.9: 138.4 $\mu / \mathrm{mL}(0-37 \mu / \mathrm{mL})$. Hormonal treatment was planned to be administered to the patient by the gynaecology and obstetrics department. During the surgery, the Levonorgestrel-Releasing Intrauterine System

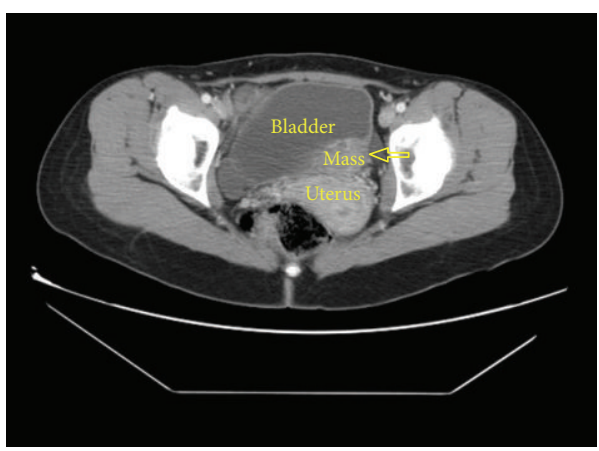

Figure 2: Abdominal contrast Computed Tomography showing a massive lesion of $3 \times 4 \mathrm{~cm}$ extending into the bladder on the left ureter orifice on the left side wall of the bladder.

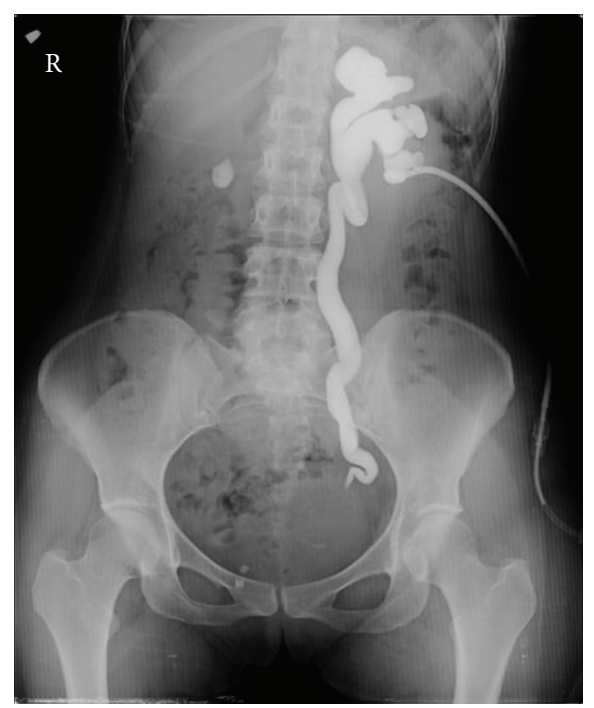

FIgURE 3: The anterograde pyelography was taken through the nephrostomy catheter and the contrast material was not transmitted to the bladder in the ureterovesical junction.

(Mirena) was inserted into the patient. After the application of LNG-IUS, while there was no reduction in the tumour markers at 3 months, when the tumour markers were evaluated at 6 months, they were seen to have receded to normal reference values. At the end of 12 months, the mass had completely recovered and the symptoms had disappeared.

\section{Discussion}

Endometriosis is seen in $3-10 \%$ of reproductive age women with complaints of pelvic pain [18]. DIE has been defined as the implantation of endometrial stroma and glandural epithelium outside the endometrial cavity and their penetration deeper than $5 \mathrm{~mm}$ into retroperitoneal regions and the surfaces of pelvic organs [19]. DIE may involve the posterior fornix, uterosacral ligament, rectum, vagina, and urinary system outside the uterus [4].

Strong data are not available regarding the prevalence of urinary system endometriosis. It is estimated that urinary 


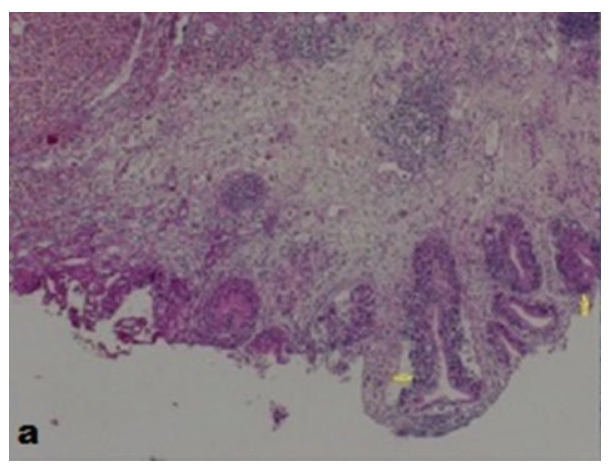

(a)

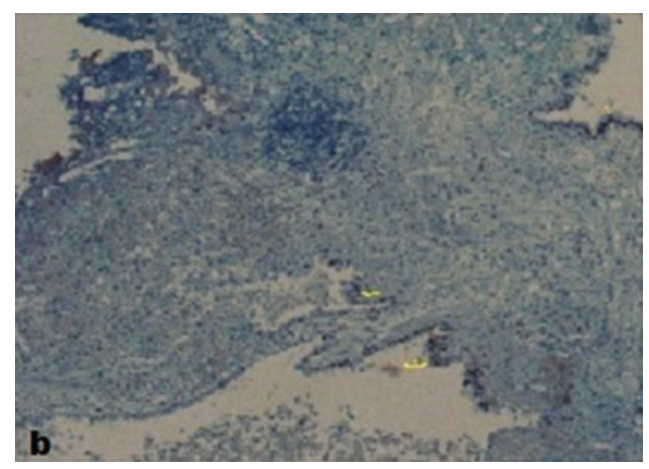

(b)

FIGURE 4: (a) Photomicrograph showing the hemosiderin-laden macrophages in the bladder wall. (Haematoxylin and eosin staining, original magnification $\times 40$.) (b) Photomicrograph showing the estrogen-containing epithelial cells in the bladder wall. (Immunohistochemical staining, original magnification $\times 40$.)

system endometriosis constitutes $1-2 \%$ of all endometriosis cases $[20,21]$. The bladder is affected by $85 \%$ of patients suffering from endometriosis involving the urinary system. The current preference for the treatment of the patients with bladder involvement is surgery, including transurethral resection or partial cystectomy followed by hormonal treatment [22].

Hydronephrosis may be observed after the exposure of the ureter, and silent renal function loss may develop in patients suffering from endometriosis in which bladder involvement is seen. Therefore, those patients should be closely monitored with renal function tests [14, 23]. Ultrasonography is the first method that should be applied, since it can be easily applied to the patient through abdominal, transvaginal, or transrectal routes depending on the complaints in the diagnosis of rare endometriosis cases such as bladder endometriosis, it is not an expensive method, and it does not cause radiation exposure [23-28]. Moreover, examination of urinary cytology plays an important role in the differential diagnosis of this disease from bladder cancer in the above-mentioned patients $[12,17]$.

Since the cells of endometriosis include estrogen and progesterone receptors, the disease responds to hormonal treatment $[29,30]$. The objective of numerous medical treatments is to accelerate the regression in endometrial tissue $[17,31-33]$. The effect of hormonal treatment is the prevention of endometriotic tissue proliferation. The general recurrence rate is $30 \%$ in patients to whom combined treatment has been applied while this rate is about 35\% in the patient group receiving only hormonal treatment [22].

Gonadotropin-releasing hormone $(\mathrm{GnRH})$ agonists and antagonists, progestin, and combined oral contraceptives are listed as the most commonly used medical treatments in endometriosis cases $[34,35]$. The utilization of local intrauterine progestin is an effective method with less systematic side effects, and LNG-IUS is the most commonly preferred agent. The expected life of this agent is five years, during which it releases $20 \mathrm{~g}$ /day levonorgestrel into the uterine cavity [36]. Theoretically, the side effects of LNG-IUS are less severe since the speed of release and systemic level are lower than stored progestin, subcutaneous implantations, and pure progestin drugs [37-47]. IUS including LNG was first used by Vercellini et al. in 1999 for treatment after endometriosis surgery [41].

LNG-IUS has both local and systemic effects in endometriosis. After the implantation of IUS, LNG-IUS directly releases an overdose of levonorgestrel into the endometrium epithelium. In this way, it prevents the proliferation of endometrial cells by decreasing estrogen and progesterone receptors, and then stromal decidualization and atrophy in endometrial glands are observed [44, 45]. In addition, it has been demonstrated that Fas, a marker of progesterone, estrogen receptors, and apoptosis, was suppressed in endometriosis cases in which LNG-IUS was administered and that this treatment contributed to the antiproliferative effect [46]. In a prospective, noncomparative LNG-IUS study of 334 patients, it was reported that LNGIUS administration treated the disease stage in $30.8 \%$ of the endometriosis cases [47].

Raised CA125 levels often accompany endometriosis and are therefore one of the most researched biomarkers. However, CA125 has low specificity in the diagnosis of endometriosis [48-50].

In the analyses related to the current case, the effects of LNG-IUS and GnRH agents on CA125 were compared in endometriosis cases. According to the data of this study, it was determined that, in the 6th month after the application of LNG-IUS, the CA 125 levels had significantly reduced and there was a positive effect of LNG-IUS on endometriosis lesions [51].

In the current patient, the tumour markers Ca 125: 92.2 (0-35) and Ca 19.9: $138.412(0-37)$ were determined before treatment. After the application of LNG-IUS, while there was no reduction in the tumour markers at 3 months, when the tumour markers were evaluated at 6 months, they were seen to have receded to normal reference values. At the end of 12 months, the mass had completely recovered and the symptoms had disappeared.

In conclusion, bladder endometriosis should be considered in the differential diagnosis for female patients with bladder masses accompanied by hydronephrosis, who suffer 
from cyclic painless hematuria attacks. LNG-IUS application may be successfully administered on its own after conservative surgery in patients experiencing moderate and severe pelvic pain due to bladder endometriosis and any other pelvic endometriosis. This treatment method is easily tolerated by the patients since side effects are limited, and the treatment has a positive effect on the patient's quality of life.

\section{Consent}

Written informed consent was obtained from the patient for publication of this case report and any accompanying images.

\section{Conflict of Interests}

The authors declare that they have no conflict of interests regarding the publication of this paper.

\section{References}

[1] P. Bellelis, J. A. Dias Jr., S. Podgaec, M. Gonzales, E. C. Baracat, and M. S. Abrão, "Epidemiological and clinical aspects of pelvic endometriosis-a case series," Revista da Associação Médica Brasileira, vol. 56, no. 4, pp. 467-471, 2010.

[2] G. M. Luscombe, R. Markham, M. Judio, A. Grigoriu, and I. S. Fraser, "Abdominal bloating: an under-recognized endometriosis symptom," Journal of Obstetrics and Gynaecology Canada, vol. 31, no. 12, pp. 1159-1171, 2009.

[3] C. Chapron, N. Chopin, B. Borghese et al., "Deeply infiltrating endometriosis: pathogenetic implications of the anatomical distribution," Human Reproduction, vol. 21, no. 7, pp. 1839-1845, 2006.

[4] C. Chapron, A. Fauconnier, M. Vieira et al., "Anatomical distribution of deeply infiltrating endometriosis: surgical implications and proposition for a classification," Human Reproduction, vol. 18, no. 1, pp. 157-161, 2003.

[5] C. Nezhat, F. Nezhat, C. H. Nezhat, F. Nasserbakht, M. Rosati, and D. S. Seidman, "Urinary tract endometriosis treated by laparoscopy," Fertility and Sterility, vol. 66, no. 6, pp. 920-924, 1996.

[6] T. S. Cullen, "Adenomyoma of the recto-vaginal septum," Bulletin of the Johns Hopkins Hospital, vol. 28, p. 243, 1917.

[7] C. Douglas and O. Rotimi, "Extragenital endometriosis-a clinicopathological review of a Glasgow hospital experience with case illustrations," Journal of Obstetrics and Gynaecology, vol. 24, no. 7, pp. 804-808, 2004.

[8] P. Collinet, F. Marcelli, A. Villers et al., "Management of endometriosis of the urinary tract," Gynecologie Obstetrique Fertilite, vol. 34, no. 4, pp. 347-352, 2006.

[9] A. M. Gustilo-Ashby and M. F. Paraiso, "Treatment of urinary tract endometriosis," Journal of Minimally Invasive Gynecology, vol. 13, no. 6, pp. 559-565, 2006.

[10] P. Yohannes, "Ureteral endometriosis," Journal of Urology, vol. 170, no. 1, pp. 20-25, 2003.

[11] J. Donnez, F. Spada, J. Squifflet, and M. Nisolle, "Bladder endometriosis must be considered as bladder adenomyosis," Fertility and Sterility, vol. 74, no. 6, pp. 1175-1181, 2000.

[12] C. H. Nezhat, S. Malik, J. Osias, and F. Nezhat, "Laparoscopic management of 15 patients with infiltrating endometriosis of the bladder and a case of primary intravesical endometrioid adenosarcoma," Fertility and Sterility, vol. 78, no. 4, pp. 872-875, 2002.

[13] G. Villa, M. Mabrouk, M. Guerrini et al., "Relationship between site and size of bladder endometriotic nodules and severity of dysuria," Journal of Minimally Invasive Gynecology, vol. 14, no. 5, pp. 628-632, 2007.

[14] L. Mettler, V. Gaikwad, B. Riebe, and T. Schollmeyer, "Bladder endometriosis: possibility of treatment by laparoscopy," Journal of the Society of Laparoendoscopic Surgeons, vol. 12, no. 2, pp. 162-165, 2008.

[15] T. Maeda, Y. Uchida, and F. Nakajima, "Vesical endometriosis following the menopause," International Urogynecology Journal and Pelvic Floor Dysfunction, vol. 20, no. 12, pp. 1515-1517, 2009.

[16] A. Fauconnier, C. Chapron, J.-B. Dubuisson, M. Vieira, B. Dousset, and G. Bréart, "Relation between pain symptoms and the anatomic location of deep infiltrating endometriosis," Fertility and Sterility, vol. 78, no. 4, pp. 719-726, 2002.

[17] O. L. Westney, C. L. Amundsen, and E. J. Mcguire, "Bladder endometriosis: Conservative management," Journal of Urology, vol. 163, no. 6, pp. 1814-1817, 2000.

[18] M. A. Fritz and L. Speroff, "Endometriosis," in Clinical Gynecologic Endocrinology and Infertility, M. A. Fritz and L. Speroff, Eds., Lippincott Williams \& Wilkins, Philadelphia, Pa, USA, 8th edition, 2011.

[19] D. L. Olive and E. Pritts, "Treatment of endometriosis," The New England Journal of Medicine, vol. 345, no. 4, pp. 266-275, 2001.

[20] J. Donnez, P. Jadoul, O. Donnez, and J. Squifflet, "Laparoscopic excision of rectovaginal and retrocervical endometriotic lesions," in Atlas of Operative Laparoscopy and Hysteroscopy, pp. 63-75, Informa UK Limited, London, UK, 2007.

[21] J. Donnez, J. Squifflet, O. Donnez, P. Jadoul, and J. Donnez, "Bladder endometriosis," in Atlas of Operative Laparoscopy and Hysteroscopy, pp. 85-91, Informa UK Limited, 2007.

[22] H. Roman, M. Vassilieff, G. Gourcerol et al., "Surgical management of deep infiltrating endometriosis of the rectum: pleading for a symptom-guided approach," Human Reproduction, vol. 26, no. 2, pp. 274-281, 2010.

[23] A. Le Tohic, C. Chis, C. Yazbeck, M. Koskas, P. Madelenat, and P. Panel, "Bladder endometriosis: diagnosis and treatment. A series of 24 patients," Gynecologie Obstetrique \& Fertilite, vol. 37, no. 3, pp. 216-221, 2009.

[24] M. J. Blumenkrantz, N. Gallagher, R. A. Bashore, and H. Tenckhoff, "Retrograde menstruation in women undergoing chronic peritoneal dialysis," Obstetrics and Gynecology, vol. 57, no. 5, pp. 667-670, 1981.

[25] M. Bazot, I. Thomassin, R. Hourani, A. Cortez, and E. Darai, "Diagnostic accuracy of transvaginal sonography for deep pelvic endometriosis," Ultrasound in Obstetrics and Gynecology, vol. 24, no. 2, pp. 180-185, 2004.

[26] L. Fedele, S. Bianchi, G. Zanconato, V. Bergamini, N. Berlanda, and L. Carmignani, "Long-term follow-up after conservative surgery for bladder endometriosis," Fertility and Sterility, vol. 83, no. 6, pp. 1729-1733, 2005.

[27] C. Balleyguier, C. Chapron, J. B. Dubuisson et al., "Comparison of magnetic resonance imaging and transvaginal ultrasonography in diagnosing bladder endometriosis," Journal of the American Association of Gynecologic Laparoscopists, vol. 9, no. 1, pp. 15-23, 2002.

[28] L. C. Giudice and L. C. Kao, "Endometriosis," The Lancet, vol. 364, no. 9447, pp. 1789-1799, 2004. 
[29] G. Leyendecker, L. Wildt, and G. Mall, “The pathophysiology of endometriosis and adenomyosis: tissue injury and repair," Archives of Gynecology and Obstetrics, vol. 280, no. 4, pp. 529538, 2009.

[30] G. Leyendecker, G. Kunz, M. Noe, M. Herbertz, and G. Mall, "Endometriosis: a dysfunction and disease of the archimetra," Human Reproduction Update, vol. 4, no. 5, pp. 752-762, 1998.

[31] T. Strowitzki, J. Marr, C. Gerlinger, T. Faustmann, and C. Seitz, "Dienogest is as effective as leuprolide acetate in treating the painful symptoms of endometriosis: a 24-week, randomized, multicentre, open-label trial," Human Reproduction, vol. 25, no. 3, pp. 633-641, 2010.

[32] A. E. Schindler, A. Henkel, C. Moore, and M. Oettel, "Effect and safety of high-dose dienogest $(20 \mathrm{mg} /$ day) in the treatment of women with endometriosis," Archives of Gynecology and Obstetrics, vol. 282, no. 5, pp. 507-514, 2010.

[33] A. E. Schindler, B. Christensen, A. Henkel, M. Oettel, and C. Moore, "High-dose pilot study with the novel progestogen dienogest in patients with endometriosis," Gynecological Endocrinology, vol. 22, no. 1, pp. 9-17, 2006.

[34] J. Brown, S. Kives, and M. Akhtar, "Progestagens and antiprogestagens for pain associated with endometriosis," Cochrane Database of Systematic Reviews, vol. 3, Article ID CD002122, 2012.

[35] J. Brown, A. Pan, and R. J. Hart, "Gonadotrophin-releasing hormone analogues for pain associated with endometriosis," The Cochrane Database of Systematic Reviews, no. 12, Article ID CD008475, 2010.

[36] T. Luukkainen, P. Lahteenmaki, and J. Toivonen, "Levonorgestrel-releasing intrauterine device," Annals of Medicine, vol. 22, no. 2, pp. 85-90, 1990.

[37] M. Du, Q. Shao, and X. Zhou, "Serum levels of levonorgestrel during long-term use of Norplant," Zhonghua Fu Chan Ke Za Zhi, vol. 34, no. 6, pp. 363-365, 1999 (Chinese).

[38] C. G. Nilsson, P. Lahteenmaki, D. N. Robertson, and T. Luukkainen, "Plasma concentrations of levonorgestrel as a function of the release rate of levonorgestrel from medicated intra-uterine devices," Acta Endocrinologica, vol. 93, no. 3, pp. 380-384, 1980.

[39] A. A. Luciano, R. N. Turksoy, and J. Carleo, "Evaluation of oral medroxyprogesterone acetate in the treatment of endometriosis," Obstetrics and Gynecology, vol. 72, no. 3, pp. 323-327, 1988.

[40] V. Odlind, "Long-term experience of a levonorgestrel-releasing intrauterine system," European Journal of Contraception and Reproductive Health Care, vol. 1, no. 4, pp. 319-323, 1996.

[41] P. Vercellini, G. Aimi, S. Panazza, O. de Giorgi, A. Pesole, and P. G. Crosignani, "A levonorgestrel-releasing intrauterine system for the treatment of dysmenorrhea associated with endometriosis: a pilot study," Fertility and Sterility, vol. 72, no. 3, pp. 505-508, 1999.

[42] Y. Bayoglu Tekin, B. Dilbaz, S. K. Altinbas, and S. Dilbaz, "Postoperative medical treatment of chronic pelvic pain related to severe endometriosis: levonorgestrel-releasing intrauterine system versus gonadotropin-releasing hormone analogue," Fertility and Sterility, vol. 95, no. 2, pp. 492-496, 2011.

[43] A. Y. Wong, L. C. Tang, and R. K. Chin, "Levonorgestrelreleasing intrauterine system (Mirena) and Depot medroxyprogesterone acetate (Depoprovera) as long-term maintenance therapy for patients with moderate and severe endometriosis: a randomised controlled trial," Australian and New Zealand Journal of Obstetrics and Gynaecology, vol. 50, pp. 273-279, 2010.
[44] R. Hurskainen, A. Salmi, J. Paavonen, J. Teperi, and E.-M. Rutanen, "Expression of sex steroid receptors and Ki-67 in the endometria of menorrhagic women: effects of intrauterine levonorgestrel," Molecular Human Reproduction, vol. 6, no. 11, pp. 1013-1018, 2000.

[45] P. Viganò, E. Somigliana, and P. Vercellini, "Levonorgestrelreleasing intrauterine system for the treatment of endometriosis: biological and clinical evidence," Women's Health, vol. 3, no. 2, pp. 207-214, 2007.

[46] M. K. O. Gomes, J. C. Rosa-E-Silva, S. B. Garcia et al., "Effects of the levonorgestrel-releasing intrauterine system on cell proliferation, Fas expression and steroid receptors in endometriosis lesions and normal endometrium," Human Reproduction, vol. 24, no. 11, pp. 2736-2745, 2009.

[47] M. Canis, J. G. Donnez, D. S. Guzick et al., "Revised American Society for Reproductive Medicine classification of endometriosis: 1996," Fertility and Sterility, vol. 67, no. 5, pp. 817-821, 1997.

[48] J. M. Escudero, J. M. Auge, X. Filella, A. Torne, J. Pahisa, and R. Molina, "Comparison of serum human epididymis protein 4 with cancer antigen 125 as a tumor marker in patients with malignant and nonmalignant diseases," Clinical Chemistry, vol. 57, no. 11, pp. 1534-1544, 2011.

[49] K. E. May, S. A. Conduit-Hulbert, J. Villar, S. Kirtley, S. H. Kennedy, and C. M. Becker, "Peripheral biomarkers of endometriosis: a systematic review," Human Reproduction Update, vol. 16, no. 6, pp. 651-674, 2010.

[50] G. A. J. Dunselman, N. Vermeulen, C. Becker et al., "ESHRE guideline: management of women with endometriosis," Human Reproduction, vol. 29, no. 3, pp. 400-412, 2014.

[51] A. C. J. de Sá Rosa e Silva, J. C. Rosa e Silva, A. A. Nogueira, C. A. Petta, M. S. Abrão, and R. A. Ferriani, "The levonorgestrelreleasing intrauterine device reduces CA-125 serum levels in patients with endometriosis," Fertility and Sterility, vol. 86, no. 3, pp. 742-744, 2006. 


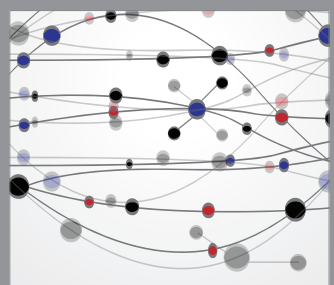

The Scientific World Journal
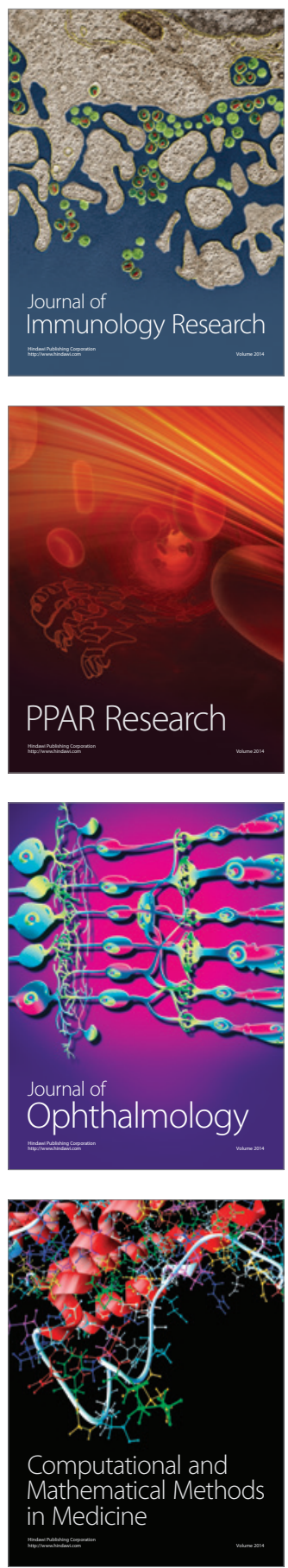

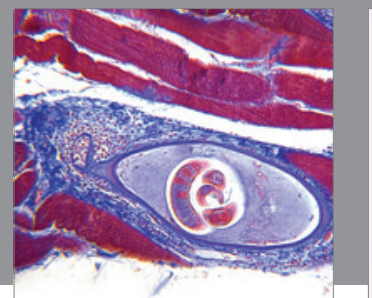

Gastroenterology

Research and Practice
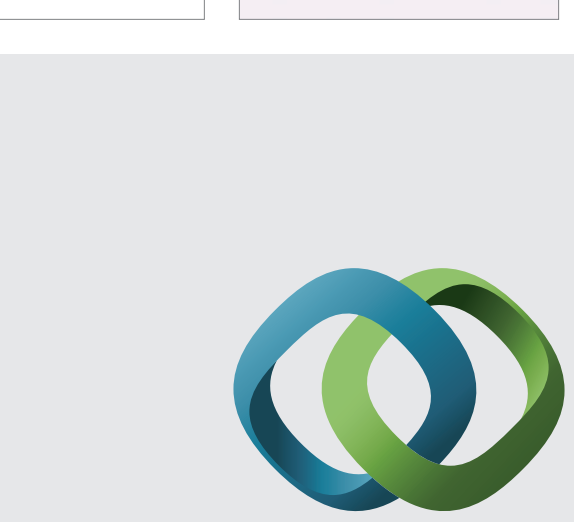

\section{Hindawi}

Submit your manuscripts at

http://www.hindawi.com
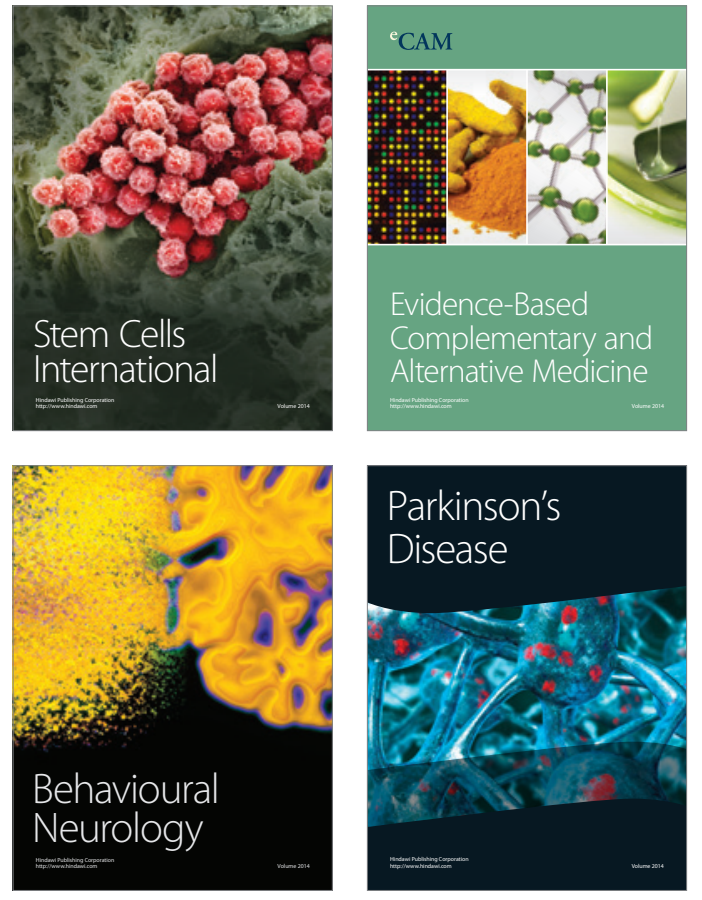
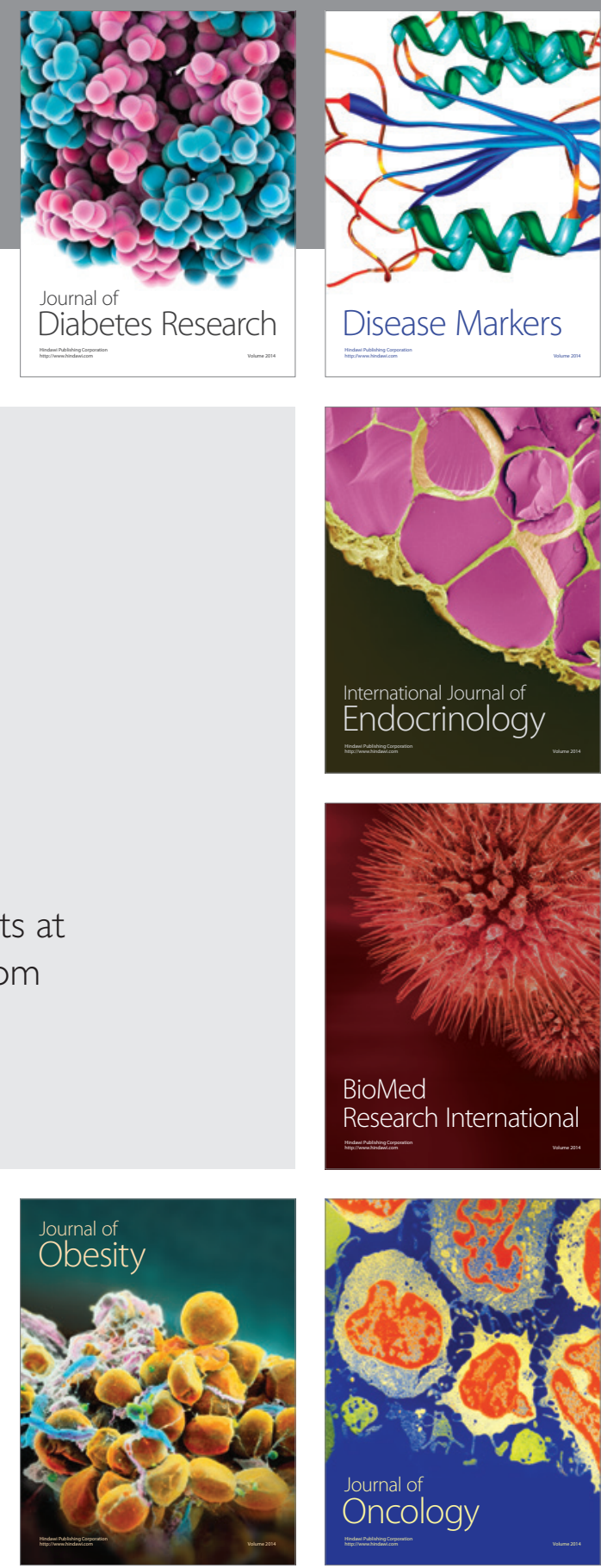

Disease Markers
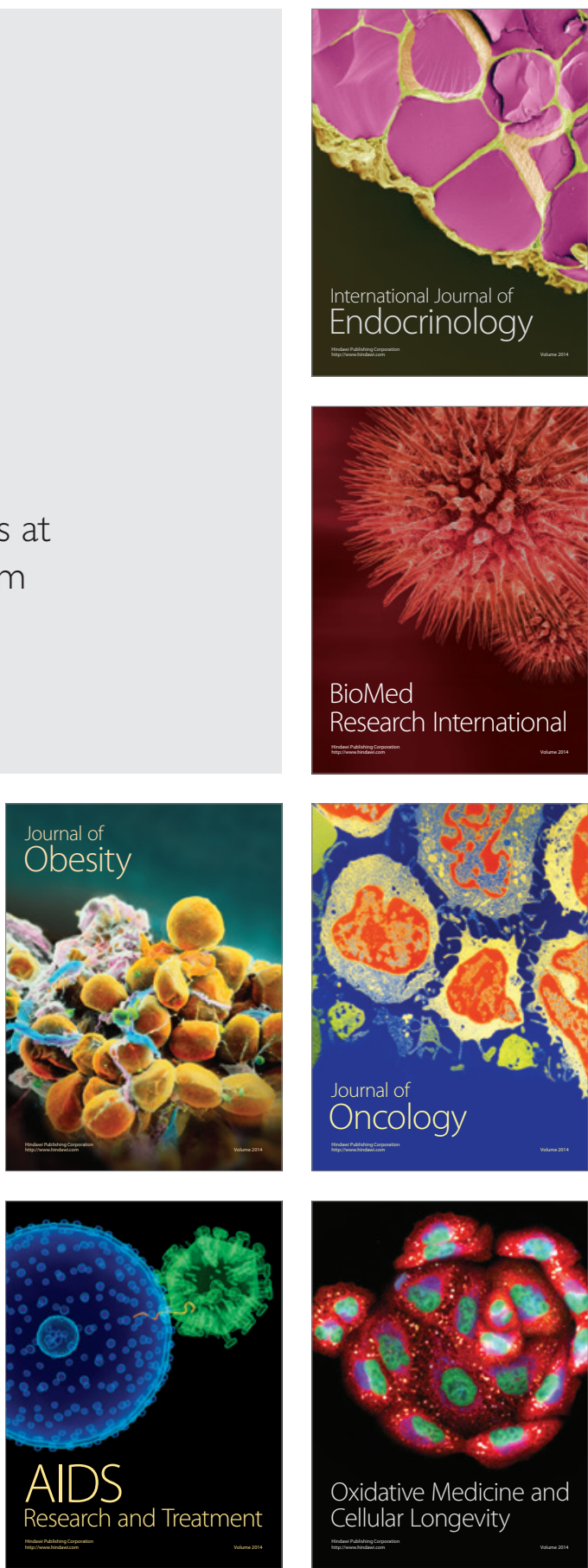